\title{
Os processos imigratórios dos séculos XIX e XX: diálogos entre o saber acadêmico e a Educação Básica
}

\section{Immigration processes of the nineteenth and twentieth centuries: dialogs between academic knowledge and Basic Education}

\author{
Cristine Fortes Lia ${ }^{1}$ \\ Roberto Radünz ${ }^{1}$
}

\begin{abstract}
RESUMO
Os estudos acadêmicos sobre os processos imigratórios para o Brasil constituem um campo fértil do conhecimento histórico, sobretudo nos programas de Pós-Graduação. Estas pesquisas, em especial as que focam as imigrações dos séculos XIX e XX, encontram pouco espaço no saber escolar. Os livros didáticos permanecem reproduzindo visões superficiais e conservadoras, de caráter cronológico e com ausência de problematizações sobre a vinda desses imigrantes europeus para terras brasileiras. Este estudo busca identificar, através da análise do material didático, utilizado nas escolas do Rio Grande do Sul, a ausência de um diálogo entre o saber acadêmico e a Educação Básica. A importância de analisar os materiais didáticos e os produtos culturais utilizados pelos professores de história da Educação Básica é cada vez mais pertinente, no sentido de investigar a concepção de conhecimento histórico que é produzido e difundido em sala de aula. Nesse sentido, a investigação sobre as práticas de docência, a partir desse objeto cultural, permite identificar lacunas que podem ser trabalhadas na formação de professores.
\end{abstract}

Palavras-chave: imigração; material didático; professores; educação.

DOI: $10.1590 / 0104-4060.46330$

1 Universidade de Caxias do Sul. Centro de Ciências Humanas e Educação. Caxias do Sul, Rio Grande do Sul, Brasil. Rua Francisco Getúlio Vargas, nº 1.130. CEP: 95.070-560. E-mails: crisflia@bol.com.bre radunz@unisc.br 


\begin{abstract}
Academic studies about immigration processes to Brazil constitute a fertile field for history knowledge, mainly in post-graduation programs. These pieces of research, particularly those that focus on immigrations of the nineteenth and twentieth centuries, find little space in school knowledge. Didactic books continue to reproduce superficial and conservative visions, of chronological character, without presenting problems arising from the arrival of those European immigrants to Brazil. This study aims at identifying, through the analysis of didactic material used at schools of Rio Grande do Sul, the absence of a dialog between academic knowledge and Basic Education. The importance of analyzing didactic material and cultural products used by History teachers of Basic Education has become more and more pertinent, in the sense of investigating the concept of historic knowledge, which is produced and diffused in class. In this sense, investigation on teachers' practices, taking this cultural object, allows us to identify some gaps, which can be used to work on teachers' education.
\end{abstract}

Keywords: immigration; didactic material; teachers; education.

\title{
Considerações iniciais
}

A imigração europeia para o estado do Rio Grande do Sul no século XIX caracteriza-se pela posse da pequena propriedade de áreas ainda não colonizadas. Os imigrantes dirigiram-se para essas regiões com o objetivo da agricultura de base familiar e com a missão de transformar economicamente e culturalmente as áreas ocupadas. Nesse processo destacam-se, numericamente, os alemães e os italianos. Diferentemente do processo do Sudeste do país, esses fluxos imigratórios não estão ligados à substituição de mão de obra escrava.

Os primeiros emigrantes germânicos chegaram ao Sul do Brasil no final do primeiro quartel do século XIX e se estabeleceram em São Leopoldo e arredores. A imigração se enquadrava naquilo que Alvin (1998, p. 235) traduziu como política que objetivava estabilizar os colonos nas suas respectivas propriedades afastando qualquer pretensão platina de retomar partes do Brasil meridional. Nessas áreas devolutas colonos foram instalados também com o objetivo de produzir alimentos para os centros urbanos. Nesse sentido, os colonos eram desejáveis como sujeitos que iriam de fato tomar posse de seu pedaço de terra. Esse quadro é típico da colonização teuto-gaúcha da primeira fase, ou seja, de 1824 até a Revolução Farroupilha. 
A imigração se intensificou depois da Guerra Civil Farroupilha (18351845) com a entrada de contingentes cada vez maiores de europeus. É nesse cenário que surgiu a Lei de Terras, um marco na estrutura fundiária. A Lei determinava que a partir daquela data as terras só poderiam ser adquiridas através da compra. No Rio Grande do Sul, com a Lei n ${ }^{\circ}$ 601, de 1854, a Província não distribuiu mais lotes gratuitos aos colonos. Só era permitida, através da Lei, a aquisição de terras mediante a compra.

Mesmo com a mercantilização das terras, o fluxo migratório para o Rio Grande do Sul se intensificou. Colônias provinciais foram criadas e, ao lado delas, surgiram também as colônias particulares. O fluxo foi tão intenso que o mapa demográfico da Província se modificou substancialmente com as áreas de colonização. Segundo Roche (1969, p. 175), nos anos de 1920 a percentagem de teuto-brasileiros no Rio Grande do Sul era da ondem de 17\% da população, chegando a $21,6 \%$ na metade do século XX.

No último quartel do século também foram ambicionados para o Sul os imigrantes italianos que saíam aos milhares da Europa. Seus destinos preferenciais eram os EUA, a Argentina e o Sudeste do Brasil. Como nem todos poderiam ser absorvidos nesses países, eles também foram desejados para desbravar a Serra Gaúcha. Herédia e Giron (2007, p. 39) apontam para uma entrada expressiva de colonos italianos no curto período de 1875 a 1914.

Segundo as autoras, “[...] entram aproximadamente 76.168 imigrantes italianos, dos quais $70 \%$ vieram entre 1875 e 1894 . Do total de imigrantes italianos chegados ao Brasil, somente cerca de 16\% fixaram-se no Rio Grande do Sul." (HERÉDIA; GIRON, 2007, p. 39). Em 1920, ainda segundo Herédia e Giron (2007), a população era composta por 924.000 habitantes, o que correspondia a $41,5 \%$ do total da população do Estado, que era de 2.226.000 habitantes. Esse quadro demográfico aponta para uma violenta europeização do estado. (HERÉDIA; GIRON, 2007, p. 40). Com esse movimento de colonização, estrategicamente o Rio Grande do Sul foi sendo ocupado desde o pampa gaúcho pelos latifúndios, os vales pelos alemães e a fatia mais íngreme, a serra, pelos italianos.

O Rio Grande do Sul do século XIX se caracterizou por um encontro de dois modelos diferentes: o latifúndio escravista e as áreas de colonização com minifúndio, policultura e mão de obra familiar. Essa distinção da estrutura produtiva oitocentista marcou o desenvolvimento econômico do Brasil meridional e explica as diferenças regionais contemporâneas.

No século XX novos grupos de imigrantes chegaram ao estado gaúcho, como judeus, de diferentes regiões da Europa, e japoneses, entre outros. Com proposta diferenciada do movimento imigratório do período anterior, esses indivíduos trouxeram contribuições para as zonas rurais e agrícolas e para as 
cidades do Rio Grande do Sul. A imigração judaica destaca-se neste cenário por corresponder a um processo diretamente ligado à região. (LIA, 2004).

Quando a necessidade de transferir judeus da Europa para a América tornou-se urgente, no final do século XIX, três regiões do continente foram apontadas, pela organização internacional que cuidava da formação de novos lares nacionais para as populações judias, Jewish Colonization Association (JCA) (em iídiche, a Yidishe Kolonizatsye Gezelshaft (ICA)), como pertinentes para receber essas pessoas: Nova Iorque, Buenos Aires e Rio Grande do Sul. Assim, a experiência judaica no Brasil iniciou-se oficialmente no extremo Sul. (LIA, 2004).

Inicialmente formaram colônias agrícolas, em cidades como Santa Maria, Erechim e Passo Fundo, que permanecem como guardiãs da memória dessa trajetória, e depois se transferiram para centros urbanos, como Porto Alegre e Pelotas. O processo de chegada e fixação dos judeus nos respectivos municípios conferiu uma dinâmica social específica, dada as características culturais e econômicas do grupo, o que conferiu uma identidade a determinados bairros. (LIA, 2004).

Os processos imigratórios dos séculos XIX e XX não correspondem apenas a um redimensionamento das formas de produção agrícola e comercial, mas caracterizam uma trajetória de transformação cultural das localidades envolvidas neles. A incorporação de novos hábitos alimentares, de diferentes idiomas, de uma estética específica, de religiosidades distintas, corresponde às múltiplas faces dessa trajetória. Uma nova identidade foi constituída para a população local através dessa experiência imigratória.

A memória da imigração constrói, ainda hoje, as referências culturais do Rio Grande do Sul, caracterizando inúmeras regiões do estado. Milhares de pessoas identificam-se através de sua ascendência imigrante. Esta, no entanto, permanece, na maioria dos casos, confinada aos festejos típicos de algumas cidades. São raros os exemplos de material didático oficial disponibilizado para a Educação Básica que dê visibilidade à imigração. A ausência de vínculo entre a memória coletiva e a história oficial promove o distanciamento do indivíduo enquanto sujeito histórico.

O século XXI inicia marcado por novos fluxos imigratórios para o Sul do Brasil. Por diferentes motivações e com distintas características culturais, senegaleses, ganeses e haitianos, entre outros, chegam em grupos expressivos ao estado gaúcho. Este processo revela a constante dinâmica da lógica da imigração e estabelece a necessidade da constante pesquisa sobre o tema. Elas, no entanto, precisam chegar à sala de aula para promover o enriquecimento da identidade nacional, desconstruindo preconceitos e preenchendo as lacunas sobre a mobilidade humana e a construção da cultura brasileira.

A visão identificada no material didático que vincula o imigrante ao trabalho livre, ou semiescravo, permite a perpetuação da ideia de que só existe sentido 
em receber novos indivíduos se estiverem destinados a uma ocupação específica. Ou que o imigrante é um usurpador do espaço profissional da população local, alimentando, muitas vezes, sentimentos de intolerância.

Nesse sentido, este estudo ocupa-se de identificar as fragilidades do material didático sobre alguns assuntos e a importância da formação do docente para problematizar algumas verdades construídas nesses materiais. Para isto, serão utilizadas obras didáticas dos anos de 2000 a 2011, utilizadas pela rede pública e privada de ensino do Rio Grande do Sul, disponíveis no acervo do Núcleo de Apoio ao Ensino de História (NAEH), da Universidade de Caxias do Sul (UCS). Os materiais compõem uma pesquisa maior, desenvolvida desde 2012, centrada nas relações entre Educação Básica e saber escolar, da linha de pesquisa Fontes e Acervos na Pesquisa e Docência em História, do Mestrado Profissional em História da UCS.

A linha se volta para a problematização dos currículos de História, usos e incorporação de fontes e acervos na pesquisa e na docência na escola e em outros espaços de aprendizagem. Os currículos de História apresentam seguidamente concepções fragmentadas do passado e o uso de fontes como forma de legitimação de verdades pré-estabelecidas ou como mera ilustração. Atendem, também, a regulamentações sociais, construindo práticas escolares que correspondem a um modelo de memória e sociedade que se pretende constituir.

Analisar os livros didáticos ${ }^{2}$ não significa necessariamente ter o estudo centrado neles, mas sim em toda a construção do conhecimento histórico realizado na Educação Básica e nas múltiplas necessidades dos docentes.

\section{A imigração no livro didático}

Existe uma sensível falta de diálogo entre as pesquisas acadêmicas e os livros didáticos no que se refere ao tema das imigrações dos séculos XIX e XX. Os programas de Pós-Graduação no Sul do Brasil têm dado especial atenção às questões relativas aos processos de imigração. Esse destaque reflete elementos da constituição demográfica, econômica, política, cultural e populacional que caracterizam a própria história do Rio Grande do Sul. Alguns stricto sensu do estado têm linhas específicas ligadas ao tema e têm acolhido propostas de trabalho que discutem essa presença distintiva ligada à imigração de alemães, italianos, poloneses, judeus, entre outros.

2 A respeito da produção no que se refere à economia política do livro didático e à sua função conferir Medeiros (2006). 
Em título de ilustração, dos seis programas acadêmicos reconhecidos pela Coordenação de Aperfeiçoamento de Pessoal de Nível Técnico (Capes), a imigração como tema consta de maneira clara em algumas linhas de pesquisa. Na Pontifícia Universidade Católica do Rio Grande do Sul (PUC/RS), o stricto sensu em História apresenta uma linha com o título "Sociedade, Urbanização e Imigração", que destaca as múltiplas formas de ocupação e de vivência social do espaço no que tange aos processos de urbanização e de imigração.

A Universidade do Vale do Rio do Sinos (UNISINOS) apresenta "Migrações, Territórios e Grupos Étnicos" como linha de pesquisa, destacando que a história da América Latina tem como uma de suas características o ingresso de populações migrantes, provenientes de outros continentes. Na Universidade de Passo Fundo (UPF), a linha de pesquisa "Espaço, Economia e Sociedade" recebe como temas de pesquisa, entre outros, a imigração e a colonização. Na Universidade Federal de Santa Maria (UFSM) a segunda linha tem como título "Migrações e Trabalho", destacando, sobretudo, a mobilidade social ligada ao tema.

A importância de analisar o livro didático centra-se no fato dele ser portador de um determinado modelo de história a ser ensinado. Ao entrar na Educação Básica, o professor perde vínculo com o material acadêmico e estabelece o norte de suas aulas através do encadeamento dos conhecimentos apresentados nos textos do referido material didático. Assim, a noção de história do Brasil, condensada em algumas páginas dessas publicações, passa a ter como filtro condutor essas obras, que são responsáveis pela construção da visão de história e de identidade nacional dos alunos.

Bittencourt (2013) chama atenção para os problemas relativos ao uso do livro didático pelo menos em dois aspectos. $O$ primeiro deles relativo ao destaque menor dado ao ensino de História do Brasil quando o recurso trata daquilo que ela traduz como macro-história, ou seja, a História Mundial. Nestes casos, a História do Brasil aparece como um apêndice da História global. Aponta que há uma tentativa de superar o problema com a produção didática denominada História Integrada, que procura introduzir o tempo sincrônico. O segundo aspecto que a autora discute é relativo à questão da identidade nacional, que via de regra está identificada com os nacionalismos de direita das fases ditatoriais.

Para fins deste texto, um outro elemento é apontado em termos de análise que merece destaque, a tendência de se trabalhar a História do Brasil como homogênea e linear. Neste sentido, "[...] a História do Brasil tem sido ensinada visando construir a ideia de um passado único e homogêneo, sem atentar para os diferentes setores sociais e étnicos que compõem a sociedade brasileira". (BITTENCOURT, 2013, p. 198).

Problematizando essa visão homogênea da História do Brasil, a autora propõe um aprofundamento das discussões relativas aos critérios de seleção de 
conteúdos que devem responder às necessidades identitárias de todos os setores sociais do atual público escolar, ou seja, "[...] a identificação dos problemas vividos ou próximos dos alunos torna possível estabelecer os objetos de estudos significativos que ordenarão os conteúdos a serem trabalhados, tanto no tempo como no espaço". (BITTENCOURT, 2013, p. 201).

Um segundo aspecto merece ser destacado, o da história local, em que é possível estabelecer relações de significado entre o conhecimento histórico e a vivência social:

Os estudos do Brasil devem contemplar a história local e regional articulada à nacional, situação que requer uma compreensão sobre a micro-história e seus fundamentos teóricos. A história local deve necessariamente estar incluída nos estudos de História, mas não exatamente na ordenação do mais próximo ao mais distante, mas de forma a ser problematizada a cada momento de estudo. (BITTENCOURT, 2013, p. 202).

O livro didático também não pode ser percebido apenas dentro do espaço da sala de aula - muitas vezes ele corresponde à referência de conhecimento histórico de toda uma família, transformando seus textos em "verdades" sobre o passado. A ausência de vínculos com eles determina a perda de posição de sujeito histórico dos seus leitores. A memória do indivíduo não corresponde ao expresso na história oficial e, muitas vezes, não encontra correspondência nos conhecimentos transmitidos pelo docente.

A ideologia expressa nesses materiais atinge toda a sociedade e conduz à consolidação de uma ideia verdadeira de história nacional. A importância de analisar os materiais didáticos e os produtos culturais utilizados pelos professores de história da Educação Básica é cada vez mais pertinente, no sentido de investigar a concepção de conhecimento histórico que é produzida e difundida em sala de aula ${ }^{3}$.

Apesar de toda a reformulação dos livros disponibilizados para a Educação Básica, os textos didáticos sobre imigração permanecem com o mesmo enfoque de décadas anteriores. Se forem comparadas as informações sobre o assunto fornecidas nos anos de 1970, 1980, 1990, 2000 e 2010, serão identificadas poucas novas abordagens sobre a vinda de imigrantes para o Brasil. Os trechos de livros expostos nos exemplos abaixo evidenciam isso.

3 A respeito de pesquisas que procuram captar a análise da educação histórica da maneira mais amplificada conferir: Schmidt e Garcia (2006). 
Os primeiros imigrantes: o senador paulista Nicolau de Campos Vergueiro foi o primeiro fazendeiro a trazer imigrantes para trabalhar na cafeicultura. Entre os anos de 1847 e 1857, levou para sua fazenda de Ibicaba, no interior de São Paulo, os primeiros grupos de imigrantes alemães, suíços e belgas. Esses imigrantes foram contratados no sistema de parceria: davam ao proprietário uma parte da colheita e ficavam com outra parte. No entanto, eram enganados e muito explorados pelos fazendeiros. Trabalhavam de sol a sol e eram tratados como escravos. Devido a isso, os imigrantes se uniram e se revoltaram contra a violenta exploração de que eram vítimas. A conseqüência foi o completo fracasso do sistema de parceria, o que desestimulou em princípio a vinda de novos imigrantes. (COTRIM, 1994, p. 201).

Em sentido semelhante:

A cafeicultura não podia contar mais com o trabalho escravo, pois o aumento da procura do produto exigia formas mais modernas de produção. O trabalho livre era a única solução. Não se poderia reutilizar os homens livres que viviam pelo sertão, pois estes se dedicavam a uma economia de subsistência e não se adaptariam a novas formas de vida. A imigração seria a melhor alternativa, mas sem cair nos erros do senador Vergueiro. (PEDRO, 2004, p. 130).

Os processos imigratórios permanecem vinculados ao continente europeu e ao século XIX, em especial, ao período de 1875. Dessa forma, a chegada das comunidades imigrantes ao Brasil está diretamente associada à imigração italiana, mantendo a ideia de imigração como substituição de mão de obra escrava. Os livros didáticos não trazem nenhuma problematização que ultrapasse a vinculação desse processo ao trabalho livre no território brasileiro.

A região Sudeste também aparece de forma privilegiada, a imigração corresponde, no texto da maior parte dos livros didáticos, à substituição do trabalho escravo pelo livre, na agricultura cafeeira de São Paulo. As imagens que ilustram as informações remetem às fazendas de plantação de café e o imigrante sempre está na função de trabalhador rural.

A experiência imigratória para a região Sul, que antecede a do Sudeste, raramente é mencionada. E, quando retratada, não é diferenciada da lógica aplicada para o Sudeste. A relação com a industrialização é negligenciada atra- 
vés de uma abordagem que engessa a percepção da imigração como trajetória específica para o trabalho agrícola.

A cultura trazida pelos imigrantes e seus processos de adaptação em terras brasileiras não têm espaço no livro didático. Enquanto meros trabalhadores, estes indivíduos são abordados como seres desprovidos de cultura, que não estabeleceram práticas de trocas com a sociedade local. Dificuldades de idioma e de vivência religiosa, características da trajetória das comunidades estrangeiras, não são mencionadas nos referidos textos.

O livro também contribui para a crença de um processo imigratório restrito ao século XIX e vinculado ao grupo numericamente pequeno de indivíduos. Nenhuma ideia de continuidade é apresentada, nem a abordagem sobre a imigração aparece em outros momentos dos livros. Assim, através desta fonte de conhecimento, a chegada dos imigrantes ao Brasil restringe-se ao Segundo Império, em que os italianos foram fixados em fazendas de café, substituindo o trabalho escravo. Sem problemas de adaptação, desapareceram da história brasileira e não tiveram antecessores e nem sucessores.

\section{FIGURA 1 - PÁGINA DE LIVRO DIDÁTICO}

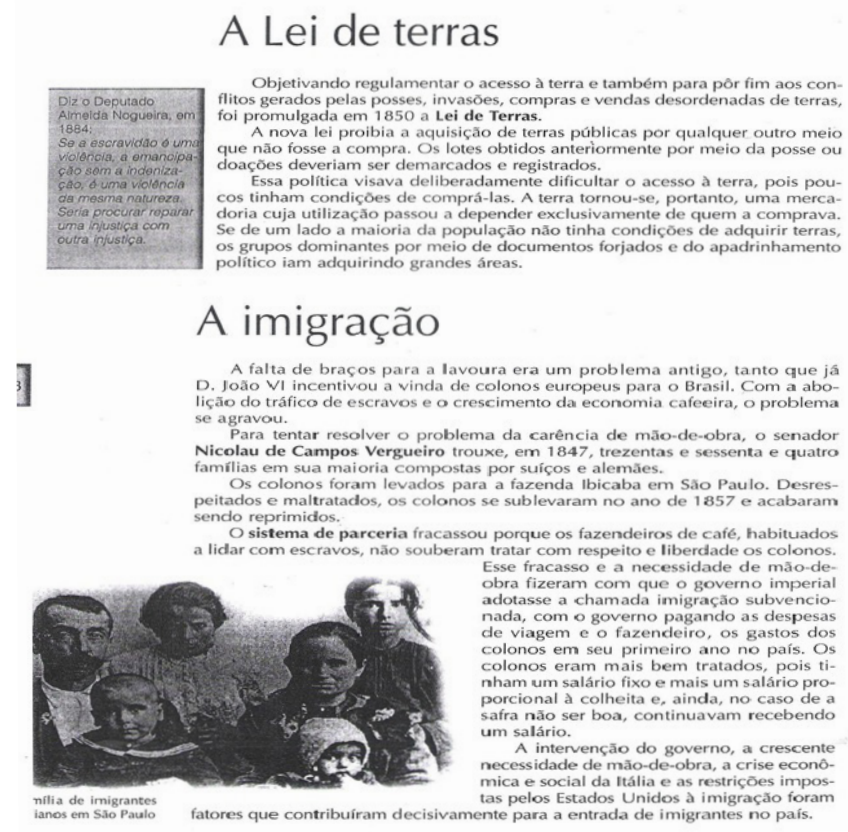

FONTE: Mocellin (2004, p. 388). 
A página do livro didático acima evidencia o que foi exposto, a imigração intimamente ligada com a Lei de Terras, ou seja, a substituição do trabalho escravo para o livre. A imagem da família imigrante, que ilustra a única parte do livro destinada ao assunto, é apenas ilustrativa, nenhuma abordagem decorre dela. Apesar da riqueza de texto que contém uma imagem, neste caso ela não é explorada. Como afirma Baldissera (2010, p. 247), “[...] cada imagem tem uma história para contar. Todas elas podem ser lidas e traduzidas em palavras, mesmo por um público não especializado."

O perfil dos indivíduos, o modelo familiar, que influenciou no modo de trabalho, as características culturais e outros aspectos são desperdiçados dentro de um contexto de informação que não lê a imagem como texto. Excessivamente focado em falar sobre a substituição de mão de obra, o texto não privilegia aspectos da imigração que poderiam ser analisados através da sua ilustração.

\section{FIGURA 2 - GRÁFICO SOBRE A ENTRADA DE IMIGRANTES NO BRASIL}

Observe o quadro:

\begin{tabular}{|c|c|c|c|}
\hline Decênios & $\begin{array}{l}\text { Imigrantes que } \\
\text { entraram no Brasil }\end{array}$ & $\begin{array}{l}\text { Imigrantes que entra- } \\
\text { ram em São Paulo }\end{array}$ & $\begin{array}{c}\% \text { de SP sobre o } \\
\text { Brasil }\end{array}$ \\
\hline $1850-1859$ & 108045 & 6310 & 5,8 \\
\hline $1860-1869$ & 106787 & 1681 & 1,6 \\
\hline $1870-1879$ & 203961 & 11730 & 5,7 \\
\hline $1880-1889$ & 453788 & 183349 & 40,1 \\
\hline
\end{tabular}

FONTE: Mocellin (2004, p. 389).

O gráfico produzido em 1976, que consta em uma obra de 2004, mantém a lógica da relação da imigração com o Sudeste. Além disso, revela que, apesar de inúmeras pesquisas produzidas sobre o tema, as fontes para o material didático ainda se encontram com data dos anos de 1970. O estado do Rio Grande do Sul recebeu a primeira leva oficial de imigrantes alemães em 1824, mas, nos dados da tabela, o movimento imigratório tem início em 1850. No Rio de Janeiro as primeiras experiências remontam ao final do período colonial. Mesmo que os números revelem que nas primeiras décadas do processo São Paulo não recebeu de forma expressiva os imigrantes, a partir de 1880 passou quase a concentrar 
este processo. Relacionando com o texto do livro, a ideia construída é que o trabalho imigrante só se tornou importante através da economia cafeeira.

A informação é construída para reforçar o sentido da entrada de imigrantes no Brasil, criando um vínculo confuso entre a história do Brasil e a história de São Paulo. Mais que isto, negligencia a experiência histórica de muitos alunos, com ascendência europeia, cuja memória familiar está ligada ao processo de trabalho imigrante. Se só foi relevante em terras paulistas, qual a importância da trajetória dos grupos do Sul do Brasil?

\section{FIGURA 3 - TEXTO SOBRE IMIGRAÇÃO NO LIVRO DIDÁTICO}

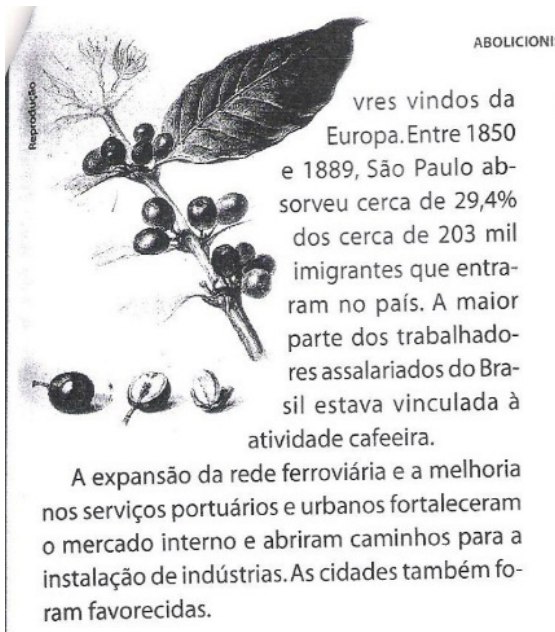

O fazendeiro, inicialmente limitado ao seu mundo rural, morando na fazenda e de hábitos conservadores, transforma-se, mais tarde, em fazendeiro citadino, que tem palacete na capital, onde desenvolve outros negócios paralelos ao do café. [...]

As cidades recebem elementos novos: advogados (vários), médicos (poucos), engenheiros (geralmente de ferrovias), professores, funcionários públicos, comerciantes, militares, imigrantes, que formam uma camada média urbana, origem da futura classe média brasileira.

(Ana Luiza Martins. Império do café. São Paulo: Atual, 1990. p. 80.)

FONTE: Rezende e Didier (2005, p. 491).

No texto acima, identifica-se, novamente, a relação entre a imigração e São Paulo. A imagem do galho com frutos de café reforça ainda mais a ideia. O livro remete a uma citação da obra "O Império do café", de 1990, para explicar o processo imigratório no Brasil, com a chegada dos imigrantes para as fazendas cafeeiras. Menciona a vida urbana dos primeiros imigrantes na capital paulista, responsáveis por formar a atual classe média brasileira. Não alude a processos anteriores, nem posteriores, de imigração urbana, nem às diversas formas culturais do processo de urbanização. 
FIGURA 4 - TRECHO DO LIVRO DIDÁTIDO SOBRE IMIGRAÇÃO

\section{O trabalho dos imigrantes}

Grande parte dos imigrantes que velo para o Brasil nessa época fol trabalhar nos cafezais, passando a viver em pequenas casas localizadas nas sedes das fazendas. De acordo com o contrato de colonato, todos os integrantes da familia, incluindo homens, mulheres e crianças, deveriam trabalhar na lavoura de cafe. Além disso, eles podiam utilizar pequenos lotes de terras, onde cultivavam cereais e legumes para sua subsistência, vendendo o excedente de sua produçăo.

Geralmente os imigrantes eram proibidos de se retirar das fazendas em que trabalhavam sem a autorizaç̄o do proprietário. Além disso, frequentemente eles eram vitimas de maus-tratos e acabavam fugindo para outras fazendas ou para as cidades, em busca de melhores condiçős de vida. Muitos desses imigrantes passaram entầ a trabalhar como artesăos, ferreiros, carpinteiros e sapateiros. Outros, ainda, empregavam-se nas indústrias, constituindo a base do operariado brasileiro.

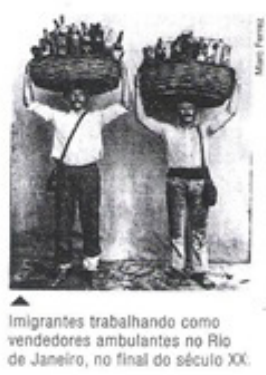

FONTE: Pellegrini, Machado e Grimberg (2010, p. 264).

A imagem que ilustra o texto acima, cuja legenda contém o equívoco de indicar o século XX, remete ao trabalho urbano dos imigrantes. Como vendedores ambulantes, função que fica pouca clara, estão novamente associados à ideia de trabalho, de natureza quase escrava. As ilustrações se repetem na maior parte das obras, bem como alguns textos, e nunca são problematizadas; correspondem a um reforço da informação contida na parte escrita. O imigrante é caracterizado, dentro desta lógica, como um sofredor, trabalhador explorado, sem especificidades culturais ou profissionais e sem expectativa de melhora de vida. Difícil associar esta construção às rememorações festivas e museus da imigração do Sul do Brasil.

Por mais que os festejos também sejam uma construção, remetem à ideia de uma nova cultura que se inseriu na sociedade brasileira. Os diferentes acervos ligados aos processos imigratórios da região Sul remontam ao cotidiano dessas comunidades, caracterizadas pelas matrizes culturais, destacando as contribuições religiosas, gastronômicas, estéticas, linguísticas, etc. A ideia de trabalho está presente, mas não de forma limitadora.

Além disso, o trabalho imigrante trouxe para o Sul do Brasil desdobres importantíssimos. Não tinha a função oficial de substituir a mão de obra escrava, mas promoveu uma euforia em torno da ideia de possuir trabalhadores, em especial domésticos, brancos. A estigmatização do trabalhador afrodescendente como inferior tem relação com a chegada dos imigrantes. Uma análise como essa não pode ser esquecida em sala de aula.

A tristeza das comunidades imigrantes expressa nos livros didáticos tem como objetivo vinculá-los aos escravos. Ligando um processo ao outro, dando linearidade às formas de exploração do trabalho no Brasil. Não se questiona a exploração das comunidades imigrantes, mas a falta de informação sobre os 
diferentes fluxos e seus objetivos, que constrói um conhecimento frágil, limitado e negligente.

FIGURA 5 - TEXTO DO LIVRO DIDÁTICO SOBRE IMIGRAÇÃO NO SUL DO BRASIL

\section{Os imigrantes do Sul}

Muitos europeus deixaram o seu país porque receberam do governo brasileiro terras no Rio Grande do Sul e em Santa Catarina, tornando-se pequenos proprietários.

Inicialmente enfrentaram enormes dificuldades, pois nào tinham recursos; além disso, não havia estradas, os meios de transporte eram os animais, a alimentação era insuficiente, etc. Aos poucos foram diversificando suas atividades, e passaram a produzir o que precisavam para sobreviver. Desenvolveram a agricultura (milho, feij) ào, batata, etc.) e a pecuária (suínos, gado, etc.), além de pequenas indústrias artesanais (queijo, salame, vinho, instrumentos de trabalho, etc.), tornando-se praticamente auto-suficientes. $O$ excedente da produção passou a ser vendido nas cidades que iam surgindo. Esses colonos do Sul, que eram pequenos proprictários. desenvolveram um padrão de vlda bastante diferente do dos colonos assalariados paulistas.

\section{Palavra-chac?}

Colono: Trabalthador rural. Em Săo Paulo, morador da colônia, conjunto de casas construidas nas fazendas para trabalhadores rurais assalariados; no Sul, proprietário de colônias, uma área de terra equivalente a 10 alqueires $\left\{242000 \mathrm{~m}^{2}\right\}$.

FONTE: Piletti e Piletti (2001, p. 181).

Em uma das raras obras didáticas que menciona a imigração no Sul do Brasil, encontra-se o texto acima. Com o objetivo de diferenciar os processos imigratórios, os dois parágrafos destinados ao assunto retratam as condições de vida da chegada dos europeus no século XIX. Nenhuma data é mencionada, como está localizado na unidade correspondente ao Segundo Império, acredita-se que tenha sido neste período, o que corresponde a uma informação equivocada. 
A palavra-chave em destaque, "colono", também remete a outro equívoco, já que no Sul nem todo o colono é proprietário de terras, menos ainda com aquelas dimensões. A colonização no Sul não tem o mesmo sentido que em São Paulo, de forma que a palavra-chave deveria questionar os diferentes processos, atribuindo sentido próprio a cada um; não se limitando a diferenciar pela posse da terra.

\section{Considerações finais}

Neste estudo foram analisados 30 livros didáticos, dos anos de 2000 a 2010, que são utilizados na rede pública e privada de ensino do Rio Grande do Sul. Destes, 11 não traziam nenhuma informação sobre os processos imigratórios de qualquer região do Brasil. Os outros 19 traziam conhecimentos como os que foram exemplificados nos parágrafos anteriores.

Nenhuma obra mencionava imigrações para além do século XIX. Os grupos que chegaram no século XX, como judeus e japoneses, estão esquecidos no livro didático. Permanece a ideia de que a imigração foi um fenômeno típico da segunda metade do século XIX. O que também negligencia as constantes experiências imigratórias e emigratórias do século XXI, pois não consolida a ideia de que são processos constantes e não lineares.

A ausência dessas informações no material pesquisado não significa que elas inexistam na totalidade dos recursos didáticos oficiais disponíveis, mas correspondem a um discurso bastante homogeneizador da trajetória dos imigrantes em terras brasileiras.

A produção de material didático no Brasil tem sido objeto de muitas pesquisas que têm focado, sobretudo, suas limitações. Ao lado dos debates relativos aos aspectos mercadológicos e editorias, esses artefatos pedagógicos quando elaborados não conseguem dar conta da pluralidade que se constitui a História do Brasil. Nesta esteira, grande parte desses livros tende a apresentar uma visão homogênea e linear a partir de seu foco mais dinâmico, o Nordeste a época da primeira etapa colonial e o Sudeste a partir do café. Neste sentido, alguns temas relevantes se tornam referência em praticamente todos os livros didáticos.

Algumas tendências atuais procuram romper com essa visão propondo uma história por eixos temáticos, o que permitiria maior autonomia no processo de seleção dos conteúdos, que se aproximariam mais das problemáticas vividas pela sociedade brasileira. Neste caso, o professor tem um papel importantíssimo na sua relação dialógica com os educandos. 
Se as limitações estão postas, cabe ao docente pesquisador procurar meios de superar esses problemas. Alguns livros didáticos já sugerem exatamente isso. No manual do professor, que se encontra como apêndice do livro Leituras da história, o docente é orientado a utilizar a história local.

Além de todas as fontes reproduzidas e citadas neste livro, é importante que você considere também a possibilidade de utilizar outras fontes que existam em seu local de atuação. Essas fontes são um recurso didático muito valioso, já que as realidades locais brasileiras são muito distintas. (CARDOSO, 2012, p. 28).

Cabe, portanto, ao professor/pesquisador, que pretende trabalhar com conhecimento significativo (SEFFNER, 2013), valer-se de fontes de pesquisa que venham a enriquecer a produção do conhecimento em sala de aula. Com a análise de alguns materiais didáticos é possível realizar com propriedade a pergunta: do que precisam os professores? Como instrumentalizá-los para trabalhar com fontes? Quais fontes devem entrar na sala de aula?

A formação docente é fundamental para romper com discursos homogeneizantes presentes nos recursos didáticos oficiais. O uso das fontes precisa acontecer de forma a construir o conhecimento junto com os educandos. Os diferentes acervos não devem ser visitados como um passeio, mas como uma leitura de uma página do livro. Para isto, os programas de formação de professores precisam estabelecer bases sólidas, capacitando os docentes a construir seus próprios recursos, transformando alunos e professores em agentes históricos.

\section{REFERÊNCIAS}

ABUD, K. Currículos de história e políticas públicas: os programas de História do Brasil na escola secundária. In: BITTENCOURT, C. (Org.). O saber histórico na sala de aula. São Paulo: Contexto, 2006.

ALVES, A.; OLIVEIRA, L. F. Conexões com a história. São Paulo: Moderna, 2010.

ALVIN, Z. Imigrantes: a vida privada dos pobres no campo. In: SEVCENKO, N. (Org.). História da Vida Privada no Brasil. São Paulo: Cia das Letras, 1998.

BALDISSERA, J. A. Imagem e construção do conhecimento histórico. In: BARROSO, V. L. M.; PEREIRA, N. M.; BERGAMASCHI, M. A.; GEDOZ, S. T.; PADRÓS, E. S. 
(Org.). Ensino de História: desafios contemporâneos. Porto Alegre: EST/Exclamação/ Anpuh-RS, 2010.

BITTENCOURT, C. Identidade nacional e ensino de História do Brasil. In: KARNAL, L. (Org.). História na sala de aula: conceitos, práticas e propostas. São Paulo: Contexto, 2013

CARDOSO, O. Leituras da história. São Paulo: Escala Educação, 2012.

COTRIM, G. História e consciência do mundo. São Paulo: Saraiva, 1994.

HERÉDIA, V; GIRON, L. S. História da Imigração Italiana no Rio Grande do Sul. Porto Alegre: Est, 2007.

LIA, C. F. Bons cidadãos: a comunidade judaica do Rio Grande do Sul durante o Estado Novo (1937-1945). Tese (Doutorado em História) - Programa de Pós-Graduação em História, Pontifícia Universidade Católica do Rio Grande do Sul, Porto Alegre, 2004.

MEDEIROS, D. H. Manuais didáticos e formação da consciência crítica. Educar, Curitiba: Editora UFPR, n. Especial, p. 73-92, 2006.

MOCELLIN, R. História. São Paulo: IBEP, 2004.

PEDRO, A.; LIMA, L. de S. História da civilização ocidental. São Paulo: FTD, 2004.

PELlEGRINI, M.; MACHADO, A.; GRIMBERG, K. Novo Olhar da História. São Paulo: FTD, 2010.

PILETTI, N.; PILETTI, C. História \& vida integrada. São Paulo: Ática, 2001.

POPKEWITZ, T. S. História do currículo, regulação social e poder. In: SILVA, T. T. da (Org.). O sujeito da educação: estudos foucaultianos. Petrópolis: Vozes, 1994.

RESENDE, A. P.; DIDIER, M. T. Rumos da história. São Paulo: Atual, 2005.

ROCHE, J. A colonização alemã e o Rio Grande do Sul. Porto Alegre: Editora Globo, 1969.

SCHMIDT, M. A. A formação do professor de história e o cotidiano da sala de aula. In: BITTENCOURT, C. (Org.). O saber histórico na sala de aula. São Paulo: Contexto, 2006.

SCHMIDT, M. A.; GARCIA, T. M. B. Pesquisa em Educação Histórica: algumas experiências. Educar, Curitiba: Editora UFPR, n. Especial, p. 11-31, 2006.

SEFFNER, F. Aprendizagens Significativas em História: critérios de construção para atividades em sala de aula. In: GIACOMONI, M. P.; PEREIRA, N. M. (Org.). Jogos e Ensino de História. Porto Alegre: Evangraf, 2013. p. 47-62.

Texto recebido em 13 de abril de 2016.

Texto aprovado em 21 de maio de 2016. 